\title{
Oxygen resuscitation and oxidative-stress biomarkers in premature infants
}

This article was published in the following Dove Press journal:

Research and Reports in Neonatology

23 May 2014

Number of times this article has been viewed

\section{Vasanth HS Kumar' \\ Vivien Carrion' \\ Karen A Wynn' \\ Lori Nielsen' \\ Anne Marie Reynolds' \\ Rita M Ryan ${ }^{2}$ \\ 'Department of Pediatrics, The Women and Children's Hospital of Buffalo, Buffalo, NY, ${ }^{2}$ Department of Pediatrics, Medical University of South Carolina, Charleston, SC, USA}

\section{Video abstract}

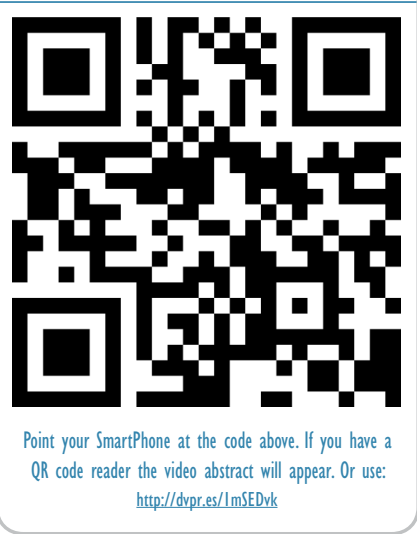

Correspondence: Vasanth HS Kumar Department of Pediatrics, The Women and Children's Hospital of Buffalo, 219 Bryant Street, Buffalo,

NY 14222-2006, USA

$\mathrm{Tel}+\mathrm{I} 7168787673$

Fax+l 7168787945

Email vkumar@upa.chob.edu
Background: Resuscitation of premature infants with $100 \% \mathrm{O}_{2}$ may initiate significant oxidant stress during development, predisposing them to bronchopulmonary dysplasia. In the study reported here, we examined the effects of three different oxygen concentrations at resuscitation on oxygen saturations $\left(\mathrm{SpO}_{2}\right)$ and oxidant stress in premature infants.

Study design: Infants $<32$ weeks gestational age were randomized to $21 \%, 40 \%$, or $100 \%$ $\mathrm{O}_{2}$ and resuscitated as per 2005 neonatal resuscitation guidelines. Oxygen groups and $\mathrm{SpO}_{2}$ were unmasked at 10 minutes of age and $\mathrm{FiO}_{2}$ adjusted to maintain an $\mathrm{SpO}_{2}$ of $85 \%-95 \%$ for the next 20 minutes. Blood was collected at 24 hours, 1 week, and 4 weeks for measurement of the oxidative-stress markers, such as a reduced glutathione (GSH) to oxidized glutathione (GSSG) ratio (GSH/GSSG), nitrotyrosine levels, and 8-hydroxydeoxyguanosine (8-OHdG) levels. The study was stopped at $30 \%$ enrollment following publication of the 2010 neonatal resuscitation guidelines.

Results: We enrolled 18 patients during the study period. $\mathrm{SpO}_{2}$ increased over time $(P<0.0001)$; however, this increase was not different among the three oxygen groups in the first 10 minutes after birth. $\mathrm{FiO}_{2}$ was significantly higher in the $100 \% \mathrm{O}_{2}$ group, despite weaning $(P<0.02)$ to maintain target saturations at 30 minutes of age. The GSH/GSSG ratio was significantly lower in the $100 \% \mathrm{O}_{2}$ group at 24 hours than in the other groups $(P<0.01)$. Plasma nitrotyrosine was significantly higher in the $40 \%$ and $100 \% \mathrm{O}_{2}$ groups over time $(P<0.01)$. Levels of $8-\mathrm{OHdG}$ were significantly higher at 4 weeks compared with at 24 hours, independent of the oxygen group $(P<0.0001)$.

Conclusion: In this study, we defined the natural evolution of $\mathrm{SpO}_{2}$ in the first 10 minutes of life with exposure to three different concentrations of oxygen. Randomization to higher $\mathrm{FiO}_{2}$ led to higher total oxygen exposure at resuscitation, and this was significantly correlated with markers of systemic oxidant stress.

Keywords: oxygen saturation, systemic oxidant stress, GSH/GSSG ratio, nitrotyrosine, resuscitation

\section{Introduction}

The transition from fetal to neonatal life in premature infants $<32$ weeks gestational age (GA) often requires some form of resuscitation, including administration of $\mathrm{O}_{2}$. However, defense mechanisms against high levels of oxygen exposure, such as antioxidant enzyme systems, are induced late in gestation ${ }^{1}$ and premature infants are not prepared to face the challenge of oxidative stress from relative hyperoxia. ${ }^{2,3}$ Resuscitation with $100 \% \mathrm{O}_{2}$ at birth induces inflammation, free-radical production, and reduced antioxidant defenses in the lungs, ${ }^{4}$ heart, ${ }^{5}$ and brain. ${ }^{6}$ Conversely, the resuscitation of premature infants with oxygen of low concentration results in lower systemic oxidative stress, inflammation, 
and incidence of bronchopulmonary dysplasia (BPD). ${ }^{7}$ Prolonged oxidative stress ${ }^{8}$ and adverse effects on mortality ${ }^{9,10}$ have been reported in term newborn infants resuscitated in $100 \% \mathrm{O}_{2}$ compared with those resuscitated in room air.

We have shown that ventilated premature lambs (born at 128 days, with lungs similar to 28 weeks' gestation) are unable to appropriately increase antioxidant enzyme activity in response to hyperoxia, and exposure to $\mathrm{O}_{2}$ aggravates systemic oxidant stress, oxidant lung injury, and pulmonary arterial contractility in lambs. ${ }^{11}$ Oxidative stress plays a role in the development of BPD with immature lungs being particularly sensitive to injurious effects of oxygen and mechanical ventilation. ${ }^{12}$ Free radicals were elevated in the plasma within 24 to 48 hours after birth, ${ }^{13}$ and in the bronchoalveolar lavage within a week, ${ }^{14}$ in premature infants who subsequently developed BPD. Plasma nitrotyrosine (NT), a marker of peroxynitrite-mediated oxidant stress is increased in the first month in infants who develop BPD; ${ }^{15}$ however, there is a paucity of literature on NT as related to oxygen resuscitation at birth. Oxygen concentrations at resuscitation may determine the degree of oxidative stress in premature neonates with decreased ability to induce antioxidant enzymes. This may trigger an inflammatory response by pro-inflammatory cytokines leading to the development of BPD. In the current study, we tested the hypothesis that limiting oxygen exposure at resuscitation in premature infants $<32$ weeks GA would decrease systemic oxidative stress as assessed by reduced glutathione (GSH) to oxidized glutathione (GSSG) ratio (GSH/ GSSG), plasma NT, and 8-hydrodeoxyguanosine (8-OHdG) at 24 hours, 1 week, or 4 weeks of age. We studied the clinical attributes in these infants, as reducing oxygen exposure should improve these outcomes. We randomized infants $<32$ weeks GA to receive one of three specified concentrations of $\mathrm{O}_{2}\left(21 \%, 40 \%\right.$, or $\left.100 \% \mathrm{O}_{2}\right)$ during resuscitation for the first 10 minutes of life. The study was conducted prior to the 2010 AHA guidelines on neonatal resuscitation ${ }^{20}$ and the purpose was to demonstrate whether premature infants $<32$ weeks GA could be resuscitated successfully in $21 \%$ or $40 \% \mathrm{O}_{2}$ and to correlate various oxygen exposures at birth with biomarkers of oxidative stress.

\section{Methods}

This study was a prospective, double-blind randomized controlled trial of the administration of three specific oxygen concentrations at birth in infants $<32$ weeks GA. Infants were enrolled from March 2009 to November 2010 at the Women \& Children's Hospital of Buffalo, New York, following institutional review board approval and written parental informed consent prior to delivery. Enrolled infants were randomized to receive $21 \%, 40 \%$, or $100 \% \mathrm{O}_{2}$ at resuscitation. Infants with known congenital or chromosomal anomalies were excluded from the study.

Immediately after birth, infants were placed on a radiant warmer and resuscitated as per 2005 Neonatal Resuscitation Program (NRP) guidelines by the AHA/AAP. ${ }^{19}$ Respiration, heart rate (HR), and color were evaluated at 30 seconds of age, after drying, stimulation, and repositioning of the infant. The study gas $\left(21 \%, 40 \%\right.$, or $\left.100 \% \mathrm{O}_{2}\right)$ assigned to each infant by randomization was delivered via a T-piece resuscitator (Neopuff ${ }^{\mathrm{TM}}$ Infant T-Piece Resuscitator; Fisher and Paykel, Auckland, New Zealand) to provide assisted ventilation as needed. The personnel in the delivery room (DR) (and all but one of the study personnel) were blinded to the study gas $\mathrm{FiO}_{2}$. Neonates who showed signs of increased difficulty in breathing initially underwent ventilation by continuous positive-airway pressure $\left(5-7 \mathrm{~cm} \mathrm{H}_{2} \mathrm{O}\right)$ with the T-piece resuscitator; positive-pressure ventilation (PPV) with facemask was followed by endotracheal intubation if needed, for lack of clinical response. Infants needing PPV were initiated with a peak inspiratory pressure of $18-20 \mathrm{~cm}$ of $\mathrm{H}_{2} \mathrm{O}$, peal end expiratory pressure of $5 \mathrm{~cm}$ of $\mathrm{H}_{2} \mathrm{O}$, and a rate of 30 to 40 per minute. Oxygen $\left(21 \%, 40 \%\right.$, or $\left.100 \% \mathrm{O}_{2}\right)$ was provided with the blender at flow rates of $8 \mathrm{~L} / \mathrm{min}$, via the T-piece resuscitator, and the peak inspiratory pressure was adjusted depending on chest rise, color, or the HR. For infants breathing spontaneously with a HR $>100$, the study gas was used to provide free-flow oxygen if needed, until they established regular respirations. Infants were switched to $100 \%$ $\mathrm{O}_{2}$ (and unmasked) only if they were not responding to the study gas (HR $<100 /$ min for $>90$ seconds) despite adequate ventilation at any time after birth and were excluded from the study. However, no infant received chest compressions or crossed over to $100 \% \mathrm{O}_{2}$ during the study period.

Soon after birth, a preductal pulse oximeter probe was placed on the infant's right hand by the study coordinator and connected to the pulse oximeter (Masimo Radical 7 SET Oximeter, Masimo Corporation, Irvine, CA, USA) to measure $\mathrm{SpO}_{2}$. Neonatal Hi-Fi sensors (LNOP Neo Masimo SET; Masimo Corporation) were used with 2-second averaging to achieve maximal sensitivity. $\mathrm{SpO}_{2}$ was recorded every 15 seconds for the first 30 minutes of life. $\mathrm{SpO}_{2}$ recordings were considered reliable when simultaneous readings of apical HR and the monitor HR were the same. Reliable $\mathrm{SpO}_{2}$ readings were established generally within 60 seconds of the birth of the infant.

The $\mathrm{FiO}_{2}$ determined at randomization was kept constant for the initial 10 minutes after birth. For the initial 10 minutes, both the $\mathrm{FiO}_{2}$ concentration and the $\mathrm{SpO}_{2}$ recordings were blinded from the resuscitation team and unmasked at 
10 minutes of life. We continued the study gas as long as the $\mathrm{SpO}_{2}$ was in the target range of $85 \%-95 \%$, and transferred the infant to the neonatal intensive care unit (NICU) in a transport isolette with the respiratory support required. $\mathrm{FiO}_{2}$ was decreased for $\mathrm{SpO}_{2}>95 \%$ and increased for $\mathrm{SpO}_{2}$ $<85 \%$, by $10 \%-20 \%$ every 60 seconds to maintain the $\mathrm{SpO}_{2}$ target of $85 \%-95 \%$. The intervention portion of the study was complete at 30 minutes of life and the $\mathrm{FiO}_{2}$ was adjusted to maintain an $\mathrm{SpO}_{2}$ of $88 \%-94 \%$ as per NICU protocol at the time. Total oxygen exposure was calculated by summation of the products of "supplemental oxygen" and the duration of $\mathrm{FiO}_{2}$ for each study infant (30 minutes) to arrive at integrated excess $\mathrm{FiO}_{2}-$ that is, $\Sigma\left(\mathrm{FiO}_{2}-0.21\right) \times$ time (minutes). ${ }^{2}$ This measurement was then correlated with biomarkers of oxidative stress. The study was stopped in December 2010 due to implementation of the 2010 NRP guidelines. The new guidelines stated clearly that $100 \%$ oxygen should not be used as the starting $\mathrm{FiO}_{2}$ during resuscitation, so we felt we could no longer randomize infants to that oxygen concentration.

\section{Biochemical measurements of oxidative stress}

Systemic oxidant stress was measured by reduced GSH/GSSG ratio, NT, and 8-OHdG in the blood. The GSH/GSSG ratio is a useful indicator of oxidative stress and also measures the effectiveness of antioxidant intervention in whole blood. NT is an indicator of peroxynitrite formation in biological systems subject to oxidative stress, and the presence of $8-\mathrm{OHdG}$ is the most common indicator of oxidative DNA damage. Blood was collected at 24 hours, 1 week, and 4 weeks of age from the central catheter (arterial or venous) or by a venous stick if a central catheter was not in place. Plasma 8-OHdG was measured at 24 hours and at 4 weeks of age.

\section{GSH/GSSG assay}

For the measurement of GSSG, $10 \mu \mathrm{L}$ of 1-methyl-2vinylpyridinium trifluoromethanesulfonate (M2VP), a thiol-scavenging reagent was added to $100 \mu \mathrm{L}$ of whole blood. M2VP rapidly scavenges GSH in whole blood. Similarly, $50 \mu \mathrm{L}$ of whole blood was collected in a microcentrifuge tube for GSH measurements. The samples were stored at $-80^{\circ} \mathrm{C}$ until the assay was performed. Calorimetric determination of reduced GSH and oxidized GSSG was performed using a Bioxytech ${ }^{\circledR}$ GSH/GSSG-412 assay kit (OxisResearch, Portland, OR, USA).

\section{NT assay}

The protein nitrotyrosine content in the sample plasma was determined by comparison with a standard curve prepared from predetermined nitrated bovine serum albumin standards. This was a competitive immunoassay for the quantitative measurement of NT in plasma (OxiSelect ${ }^{\mathrm{TM}}$ Nitrotyrosine ELISA [enzyme-linked immunosorbent assay] Kit, STA-305; Cell Biolabs, Inc., San Diego, CA, USA).

\section{8-OHdG assay}

The OxiSelect ${ }^{\mathrm{TM}}$ DNA Damage ELISA kit (STA-320; Cell Biolabs, Inc.) is a competitive enzyme immunoassay developed for rapid detection and quantitation of $8-\mathrm{OHdG}$ in serum. The quantity of $8-\mathrm{OHdG}$ in a sample was determined using this kit by comparing its absorbance with that of a known 8-OHdG standard curve.

\section{Data collection to assess primary and secondary study outcomes}

The primary outcome of the study was GSH/GSSG ratio at 24 hours of age. Based on our preterm lab studies, to detect a difference of 1.5 with a standard deviation (SD) of 1.5 in GSH/GSSG ratio at 24 hours with an alpha level of 0.05 and power of $80 \%$, it was estimated that each group would require 20 patients. The three oxygen groups were stratified into two subgroups (23-27 6/7 weeks; 28 0/7-31 $6 / 7$ weeks) and infants were randomized within stratified groups to ensure homogeneity among the groups (21\%, 40\% and $100 \% \mathrm{O}_{2}$ ).

Although not powered for these secondary outcomes, we also collected data regarding mortality, BPD (oxygen requirement at 36 weeks), necrotizing enterocolitis (NEC; stage II or higher), patent ductus arteriosus (PDA), and intraventricular hemorrhage (IVH) in these infants. All data are expressed as mean $\pm \mathrm{SD}$, with " $n$ " being the number of infants in each group. Student's $t$-test was used to analyze certain characteristics such as intubation and GA among the oxygen groups, and to analyze plasma $8-\mathrm{OHdG}$ at 24 hours and 4 weeks in the three oxygen groups. The three oxygen groups were compared by one-way analysis of variance (ANOVA). When the overall comparison was significant, differences between individual groups were analyzed using the Tukey-Kramer method (with SAS software version 9.2 [SAS Institute, Cary, NC, USA]). A $P$-value of $<0.05$ was considered significant.

\section{Results}

We enrolled 18 infants during March 2009 through November 2010 and the study was stopped December 2010 with the implementation of 2010 AHA guidelines on neonatal resuscitation. Six infants were randomized to resuscitation with $21 \% \mathrm{O}_{2}$, seven infants with $40 \% \mathrm{O}_{2}$, and five infants 


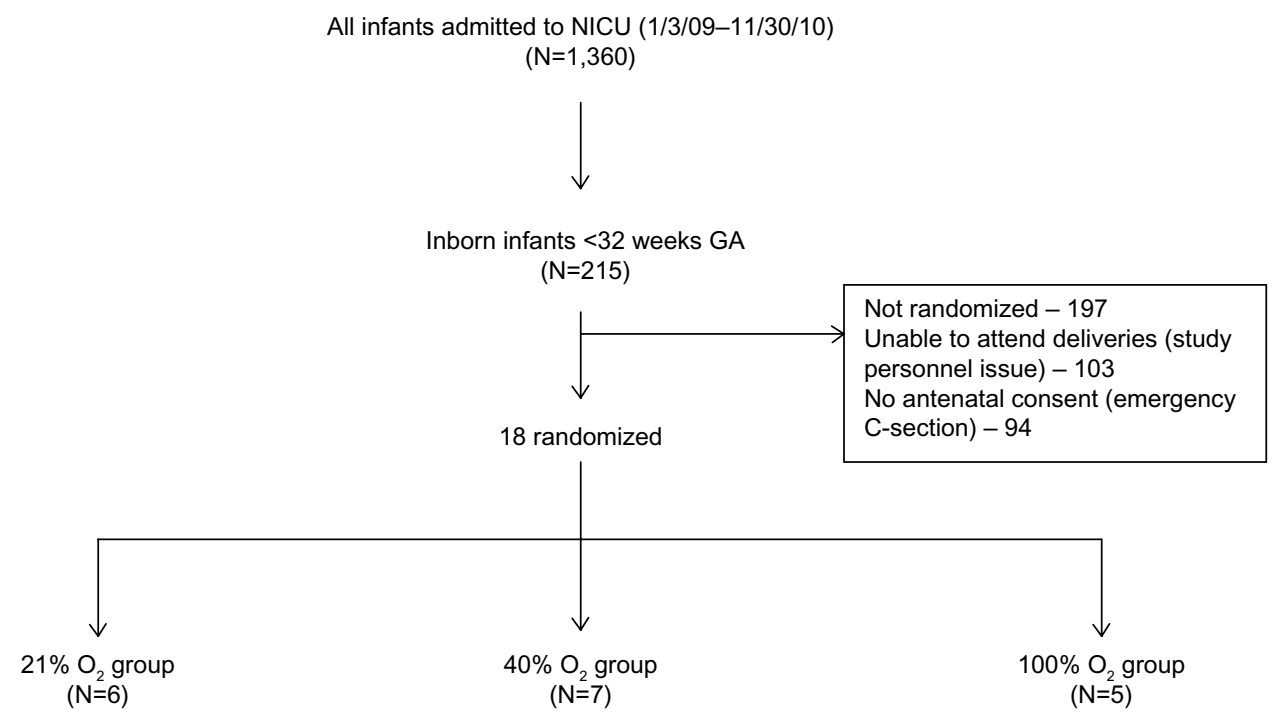

Figure I Trial flow chart displaying the distribution of infants during the study period.

Abbreviations: NICU, neonatal intensive care unit; C-Section, Cesarean section; GA, gestational age.

with $100 \% \mathrm{O}_{2}$ (Figure 1). Baseline characteristics, respiratory support at birth, blood gas on admission to the NICU, and total oxygen exposure in the three groups are shown in Table 1 . Infants in the $100 \% \mathrm{O}_{2}$ group were trending to be of lower GA (Table 1); however, this was not significant

Table I Baseline characteristics, respiratory support at birth, and initial arterial blood gas (ABG) in the three resuscitated groups ${ }^{a}$

\begin{tabular}{|c|c|c|c|}
\hline & $\begin{array}{l}21 \% \text { group } \\
(n=6)\end{array}$ & $\begin{array}{l}40 \% \text { group } \\
(n=7)\end{array}$ & $\begin{array}{l}100 \% \text { group } \\
(n=5)\end{array}$ \\
\hline \multicolumn{4}{|l|}{ Baseline characteristic } \\
\hline Gestational age (weeks) & $29.3 \pm 2.3$ & $28.1 \pm 2.6$ & $28.0 \pm 2.2$ \\
\hline Birth weight (g) & $\mathrm{I}, \mathrm{I} 82 \pm 340$ & $\mathrm{I}, 149 \pm 440$ & $1,139 \pm 374$ \\
\hline Sex, n male (\%) & $2(33)$ & $5(7 I)$ & $3(60)$ \\
\hline Prenatal steroids & 100 & 100 & 100 \\
\hline C-section, n (\%) & $6(100)$ & $6(85)$ & $4(80)$ \\
\hline Cord blood pH & $7.28 \pm 0.04$ & $7.32 \pm 0.05$ & $7.33 \pm 0.06$ \\
\hline Apgar (5 minutes) & $9(8-9)$ & $9(8-9)$ & $8(8-9)$ \\
\hline \multicolumn{4}{|c|}{ Respiratory support at birth } \\
\hline CPAP only, $n$ & 2 & 2 & 1 \\
\hline PPV, n (\%) & $3(50)$ & $5(7 I)$ & $4(80)$ \\
\hline Intubation in DR, n (\%) & $2(33)$ & $4(57)$ & $4(80)$ \\
\hline Surfactant in DR, n (\%) & $\mathrm{I}(\mathrm{I7})$ & $3(43)$ & $4(80)$ \\
\hline \multicolumn{4}{|c|}{ Initial $A B G$ at 60 minutes of life } \\
\hline $\mathrm{pH}$ & $7.32 \pm 0.05$ & $7.33 \pm 0.04$ & $7.30 \pm 0.07$ \\
\hline $\mathrm{PaCO}_{2}(\mathrm{mmHg})$ & $45 \pm 6$ & $43 \pm 3$ & $45 \pm 5$ \\
\hline $\mathrm{PaO}_{2}(\mathrm{mmHg})$ & $65 \pm 7$ & $68 \pm 8$ & $55 \pm 8$ \\
\hline Base deficit & $3.5 \pm 0.9$ & $3.7 \pm 0.9$ & $4.3 \pm 1.1$ \\
\hline \multicolumn{4}{|c|}{ Total oxygen exposure, $\left(\mathrm{FiO}_{2}\right.$ delivered $\left.-0.2 \mathrm{I}\right) \times$ time (minutes) } \\
\hline $\begin{array}{l}\text { At } 30 \text { minutes old } \\
\text { (end of intervention) }\end{array}$ & $0.23 \pm 0.21^{*}$ & $3.89 \pm 0.95$ & $14.04 \pm 2.83$ \\
\hline
\end{tabular}

Notes: ${ }^{a}$ alues are expressed as mean \pm standard deviation unless otherwise specified. $* P<0.00 \mathrm{I}$ versus $40 \% \mathrm{O}_{2}$ and $100 \% \mathrm{O}_{2}$ (analysis of variance).

Abbreviations: CPAP, continuous positive-airway pressure; DR, delivery room; PPV, positive-pressure ventilation; C-section, Cesarean section.
$(P=0.3)$. There were no differences in birth weight or other characteristics among the three $\mathrm{O}_{2}$ resuscitated groups (Table 1). More infants in the $100 \% \mathrm{O}_{2}$ resuscitated group were intubated and administered surfactant in the DR than in the other two groups (Table $1 ; 80 \%$ in the $100 \% \mathrm{O}_{2}$ group, $43 \%$ in the $40 \% \mathrm{O}_{2}$ group, and $17 \%$ in the $21 \% \mathrm{O}_{2}$ group). Infants who were intubated had a significantly lower GA $(27.2 \pm 2.1$ vs $30.1 \pm 1.4 ; P<0.003)$. However, there was no significant difference in intubated patients among the oxygen groups $(P=0.06)$. There were no differences in blood-gas parameters, such as $\mathrm{pH}, \mathrm{PaCO}_{2}, \mathrm{PaO}_{2}$, and base deficit, as assessed at 60 minutes after birth among the three groups (Table 1). Total oxygen exposure during the study period was significantly different among the groups: the $100 \% \mathrm{O}_{2}$ group had the highest oxygen exposure $\left(P<0.0001\right.$ vs $21 \% \mathrm{O}_{2}$ and $40 \%$ $\mathrm{O}_{2}$; ANOVA) and the $21 \% \mathrm{O}_{2}$ group had the lowest oxygen exposure $\left(P<0.001\right.$ vs $\left.40 \% \mathrm{O}_{2}\right)$ (Table 1$)$.

\section{$\mathrm{FiO}_{2}$ and $\mathrm{SpO}_{2}$ values}

Figure 2 illustrates the mean $\mathrm{SpO}_{2}$ values in the first 10 minutes of life in the three oxygen resuscitated groups. The mean $\mathrm{SpO}_{2}$ values were $50 \%, 53 \%$, and $69 \%$ at 1 minute; $77 \%, 83 \%$, and $95 \%$ at 5 minutes; and $92 \%, 92 \%$, and $98 \%$ at 10 minutes in the $21 \% \mathrm{O}_{2}, 40 \% \mathrm{O}_{2}$, and $100 \% \mathrm{O}_{2}$ groups, respectively (Figure 2). There was no significant difference in $\mathrm{SpO}_{2}$ among the three oxygen groups at any given minute in the first 10 minutes of life. However, there was a trend toward significance at 5 minutes of life among the groups $(P=0.06) . \mathrm{SpO}_{2}$ significantly increased over time in the first 10 minutes of life in all the three oxygen groups $(P<0.0001$; 


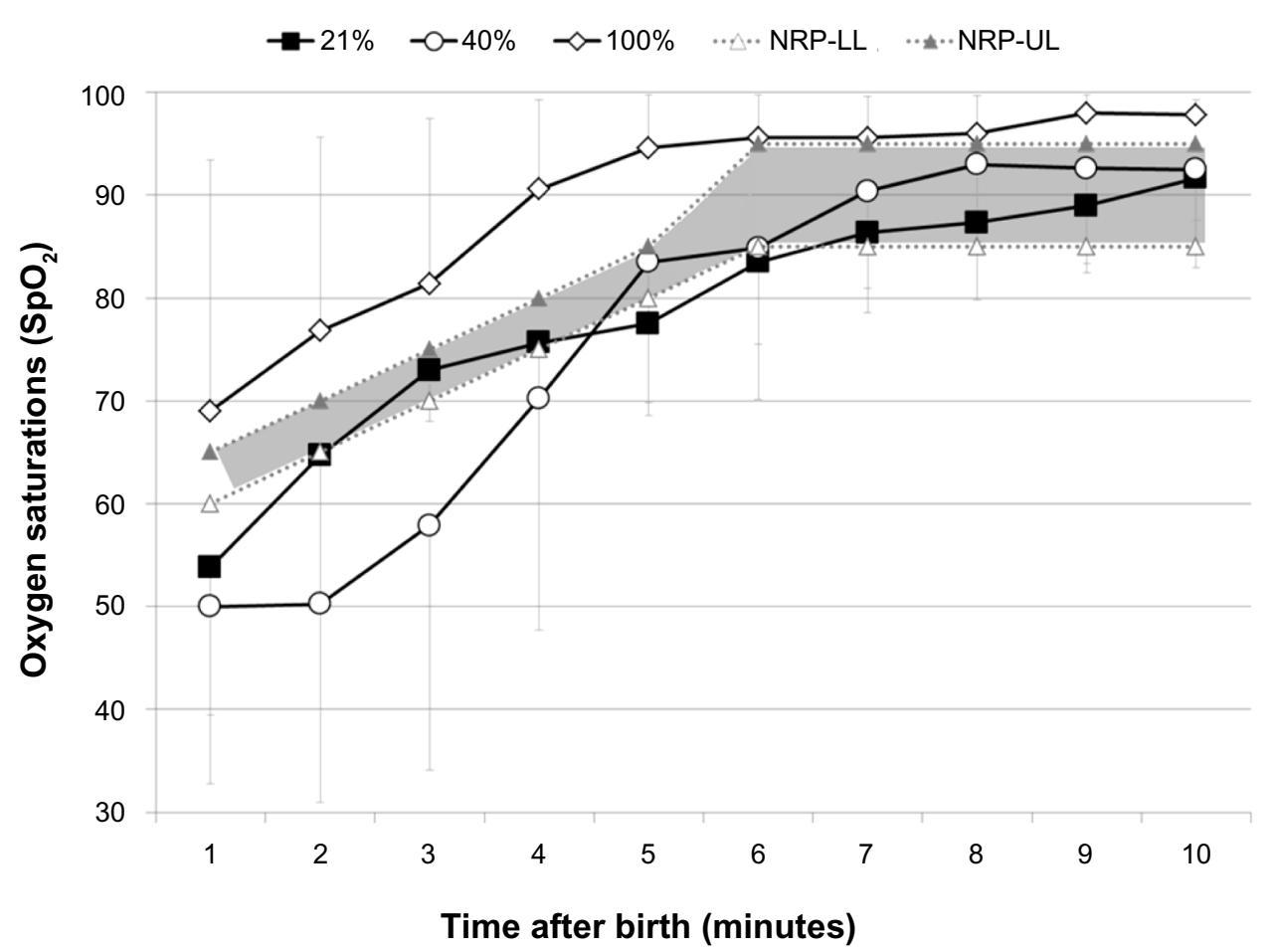

Figure 2 Oxygen saturations $\left(\mathrm{SpO}_{2}\right)$ in premature infants $<32$ weeks gestational age during the first 10 minutes after birth in the three resuscitated groups. Oxygen was kept constant for the first 10 minutes at either $21 \% \mathrm{O}_{2}(-m-), 40 \% \mathrm{O}_{2}(-\circ-)$, or $100 \% \mathrm{O}_{2}\left(-\nabla_{-}\right)$in each of the three groups. Each time point represents mean \pm standard deviation. SpO significantly increased over time in the first 10 minutes after birth in all infants $\left(P<0.000 \mathrm{I}\right.$ mixed-model analysis of variance). Upper $\left(\cdots \mathbf{\Delta}^{\prime} \cdots\right)$ and lower $\left(\cdots \Delta^{\cdots} \cdots\right)$ SpO $\mathrm{O}_{2}$ limits $(20 \mathrm{I} 0$ AHA guidelines on neonatal resuscitation) ${ }^{20}$ are superimposed on the $\mathrm{SpO}_{2}$ curves of the three $\mathrm{O}_{2}$ resuscitated groups. The NRP SpO ${ }_{2}$ range has been shaded gray for easy interpretation. $\mathrm{SpO}_{2}$ with $100 \% \mathrm{O}_{2}$ was above the NRP upper limit (UL); resuscitation with $21 \%$ or $40 \% \mathrm{O}_{2}$ maintained $\mathrm{SpO}_{2}$ within the NRP range from 5 to 10 minutes of life. Abbreviation: LL, lower limit.

mixed-model ANOVA). However, oxygen groups alone $(P=0.08)$ or in combination with time $(P=0.36)$, were not significantly correlated with $\mathrm{SpO}_{2}$ in the first 10 minutes after birth. Resuscitation of premature infants with $100 \%$ $\mathrm{O}_{2}$ resulted in $\mathrm{SpO}_{2}$ values above the upper limit of the 2010 guidelines in the first 10 minutes after birth (Figure 2). The $40 \% \mathrm{O}_{2}$ resuscitated group had $\mathrm{SpO}_{2}$ values below the NRP lower limit in the first 5 minutes and within the range by 6-10 minutes of age (Figure 2). Similarly, the $21 \% \mathrm{O}_{2}$ resuscitated group had mean $\mathrm{SpO}_{2}$ values bordering the NRP lower limit in the first 5 minutes and within the NRP-defined $\mathrm{SpO}_{2}$ target range from 6 to 10 minutes. There were no differences in $\mathrm{SpO}_{2}$ among the groups at 10 and 30 minutes of life.

$\mathrm{FiO}_{2}$ was weaned to maintain $\mathrm{SpO}_{2}$ in the target range of $85 \%-95 \%$ from 10 minutes of age. Infants in the $21 \% \mathrm{O}_{2}$, $40 \% \mathrm{O}_{2}$, and $100 \% \mathrm{O}_{2}$ groups were weaned to $24.8 \%( \pm 5)$, $27.9 \%( \pm 6)$, and $38 \%( \pm 20) \mathrm{O}_{2}$, respectively, at 30 minutes of age (Figure 3). Despite aggressive weaning, $\mathrm{FiO}_{2}$ was significantly higher in the $100 \% \mathrm{O}_{2}$ group to maintain the target $\mathrm{SpO}_{2}$ until 30 minutes of age $\left(P<0.02\right.$ vs $40 \% \mathrm{O}_{2}$ and $21 \% \mathrm{O}_{2}$ groups; ANOVA). There was no significant difference in $\mathrm{FiO}_{2}$ between the $40 \% \mathrm{O}_{2}$ and $21 \% \mathrm{O}_{2}$ groups during the weaning process (Figure 3). HR following resuscitation increased significantly over time in the first 10 minutes in all the three oxygen groups ( $P<0.0001$, ANOVA), although this was not significant among them.

\section{Oxygen resuscitation and oxidative-stress markers}

Over time, whole-blood GSH concentrations were significantly higher in the $21 \% \mathrm{O}_{2}$ group compared with the $40 \%$ $\mathrm{O}_{2}$ and $100 \% \mathrm{O}_{2}$ groups $\left(P<0.01\right.$ vs the $40 \%$ and $100 \% \mathrm{O}_{2}$ groups; two-way ANOVA; Table 2). Blood GSSG levels were significantly higher at 24 hours in the $100 \% \mathrm{O}_{2}$ group compared with the other two groups $(P<0.01)$; however, this was not different over time ( 1 week and 4 weeks) among the groups (Table 2). The GSH/GSSG ratio was significantly lower at 24 hours in the $100 \% \mathrm{O}_{2}$ group compared with the $21 \% \mathrm{O}_{2}$ and $40 \% \mathrm{O}_{2}$ groups $(P<0.01$; Table 2$)$, suggesting higher oxidative stress in this group (Figure 4). The ratio was not different among the groups at 1 week or at 4 weeks of age.

Plasma NT, a marker of peroxynitrite formation, was higher in the two oxygen resuscitated groups over time (Figure 5A) $\left(P<0.01\right.$ vs the $40 \% \mathrm{O}_{2}$ group; $P<0.001$ vs 


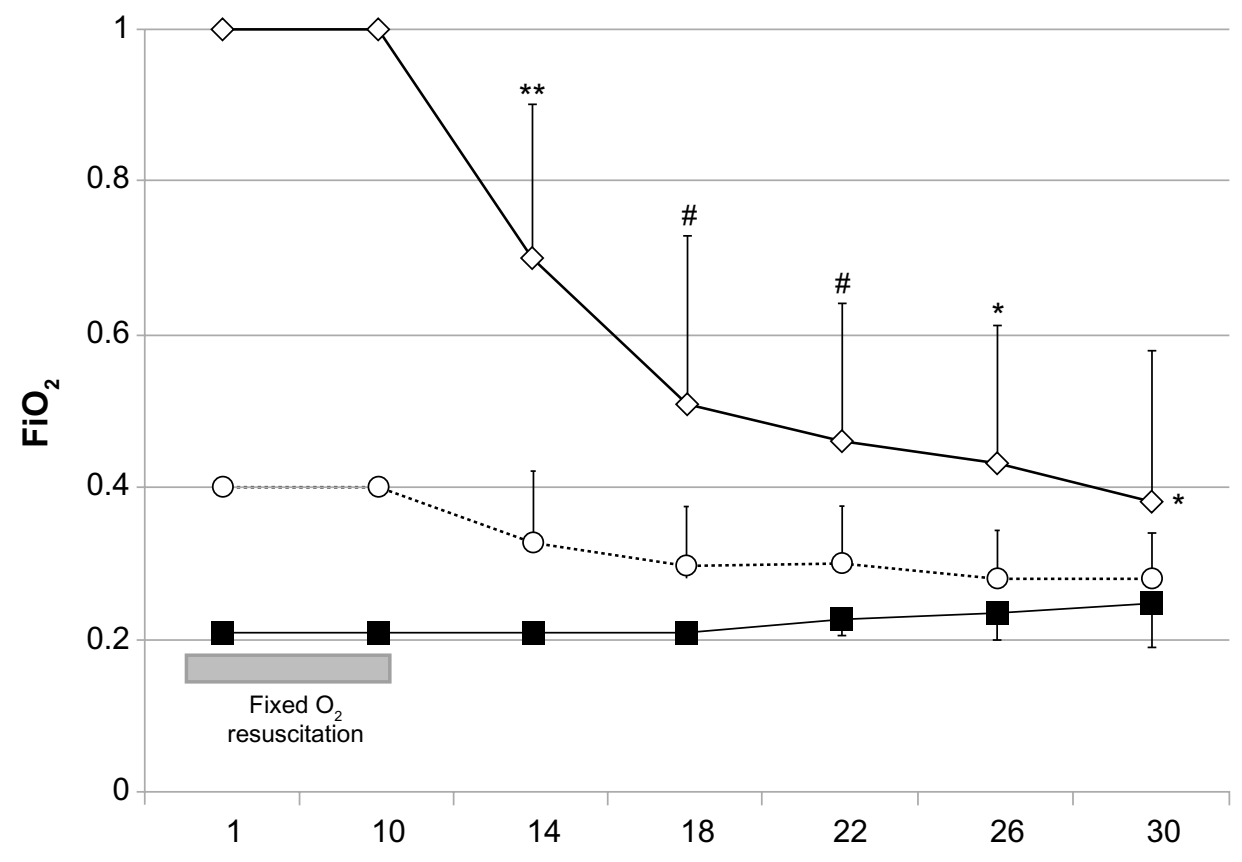

Time after birth (minutes)

Figure $3 \mathrm{FiO}_{2}$ in the first 30 minutes after birth in the three oxygen resuscitated groups. Oxygen was kept constant during resuscitation for the first 10 minutes after birth at either $21 \% \mathrm{O}_{2}(--), 40 \% \mathrm{O}_{2}(-\circ-)$, or $100 \% \mathrm{O}_{2}\left(-\nabla_{-}\right)$in each of the three groups. $\mathrm{FiO}_{2}$ was adjusted from 10 to 30 minutes of age for a target $\mathrm{SpO}$ of $85-95$. FiO ${ }_{2}$ was significantly higher in the $100 \% \mathrm{O}_{2}$ group to maintain the target $\mathrm{SpO}_{2}$ from 10 to 30 minutes of age.

Notes: $* P<0.02$ versus $40 \% \mathrm{O}_{2}$ and $21 \% \mathrm{O}_{2}$ groups (mixed-model repeated measure); ${ }^{*} P<0.0001 ;{ }^{*} P<0.002 ; * P<0.02$ versus $40 \% \mathrm{O}_{2}$ and $21 \% \mathrm{O}_{2}$ groups (analysis of variance).

$100 \% \mathrm{O}_{2}$ group). Also, the $100 \% \mathrm{O}_{2}$ group had higher $\mathrm{NT}$ compared with the other two groups at 24 hours $(P<0.01$; Figure 5A). Levels of $8-\mathrm{OHdG}$ were similar at 24 hours and at 4 weeks among the groups; however, they were significantly higher at 4 weeks compared with at 24 hours among the groups $\left(P<0.0001^{*}\right.$; Figure 5B).

\section{Secondary outcomes}

There were no significant differences in any of the secondary outcomes measured in the study. The incidence of any IVH was $40 \%$ in the $100 \% \mathrm{O}_{2}$ group (bilateral Grade I in one infant and I/II in another) and none in the other groups. We had one infant with significant PDA in each of the $40 \%$ $\mathrm{O}_{2}$ and $100 \% \mathrm{O}_{2}$ groups. The incidence of BPD was $16 \%$ $(1 / 6), 42 \%(3 / 7)$, and $60 \%(3 / 5)$ in the $21 \% \mathrm{O}_{2}, 40 \% \mathrm{O}_{2}$, and
$100 \% \mathrm{O}_{2}$ groups, respectively. Infants in the $21 \% \mathrm{O}_{2}$ group were ventilated for a mean of $2.6( \pm 5.6)$ days compared with $7.3( \pm 10)$ days in the $40 \% \mathrm{O}_{2}$ group and $26.4( \pm 27.3)$ days in the $100 \% \mathrm{O}_{2}$ group; this was not significant among the groups $(P=0.06)$. One infant in the $21 \% \mathrm{O}_{2}$ group and one in the $40 \% \mathrm{O}_{2}$ group died, while no infants in the $100 \% \mathrm{O}_{2}$ group died. The combined outcome for BPD, NEC, or death was $50 \%(3 / 5), 71 \%(5 / 7)$, and $100 \%$ in the $21 \% \mathrm{O}_{2}, 40 \% \mathrm{O}_{2}$, and $100 \% \mathrm{O}_{2}$ resuscitated groups, respectively.

\section{Discussion}

Multiple studies have addressed oxygen administration at resuscitation by variation in oxygen titration strategies in the first 10 minutes after birth. ${ }^{16-18}$ The novelty of our study was in modifying this approach to allow for a fixed concentration

Table 2 Reduced glutathione (GSH), oxidized glutathione (GSSG), and the GSH to GSSG ratio in the three resuscitated groups

\begin{tabular}{|c|c|c|c|c|c|c|c|c|c|}
\hline \multirow[t]{2}{*}{ Group } & \multicolumn{3}{|l|}{ GSH } & \multicolumn{3}{|l|}{ GSSG } & \multicolumn{3}{|c|}{ GSH/GSSG } \\
\hline & 24 hours & I week & 4 weeks & 24 hours & I week & 4 weeks & 24 hours & I week & 4 weeks \\
\hline $21 \% \mathrm{O}_{2}$ & $\mathrm{I}, \mathrm{I} 38(92)$ & $\mathrm{I}, 402(229)$ & $1,268 *(75)$ & $7.1(0.3)$ & $5.1(1.9)$ & $4.3(0.2)$ & $159(14)$ & 275 & $294(12)$ \\
\hline $40 \% \mathrm{O}_{2}$ & I,I06 (94) & $910(72)$ & $853(78)$ & $6.1(0.3)$ & $4.0(0.3)$ & $3.1(0.4)$ & $180(12)$ & $227(16)$ & $280(16)$ \\
\hline $100 \% \mathrm{O}_{2}$ & $\mathrm{I}, 047(\mathrm{I} 52)$ & $960(201)$ & $\mathrm{I}, 024$ (I54) & $12.0 * *(2.1)$ & $4.5(0.3)$ & $4.0(0.1)$ & $88^{a}(10)$ & $210(9)$ & $297(28)$ \\
\hline
\end{tabular}

Notes: Values are expressed as mean (standard deviation); GSH and GSSG were measured at 24 hours and at the end of first and fourth weeks of life, and expressed as $\mu$ M in a fixed sample of whole blood. GSH levels were significantly higher in the $21 \% \mathrm{O}_{2}$ group $\left(* P<0.0\right.$ I versus $40 \%$ and $100 \% \mathrm{O}_{2}$ group; ANOVA); GSSG was higher in I00\% $\mathrm{O}_{2}$ group ( ${ }^{*} \mathrm{P}<0.0 \mathrm{I}$ versus $40 \%$ and $21 \% \mathrm{O}_{2}$ groups; ANOVA) at 24 hours; however, GSSG levels were not different among the groups over time; ${ }^{\mathrm{a} G S H} / \mathrm{GSSG}$ ratio was significantly lower in the $100 \% \mathrm{O}_{2}$ resuscitated group $(P<0.0$ I, versus $21 \%$ and $40 \%$ groups; ANOVA) at 24 hours. 


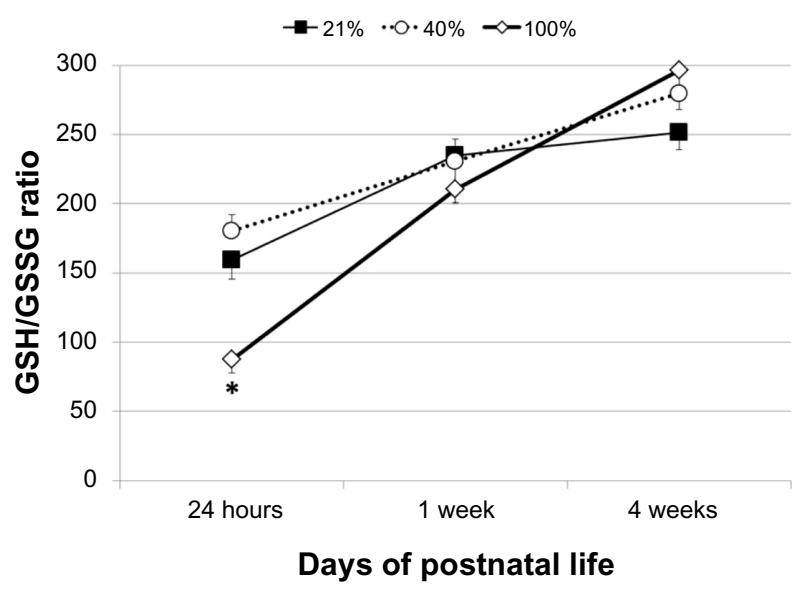

Figure 4 Glutathione (GSH) and oxidized glutathione (GSSG) were measured in whole blood in the three resuscitated groups $\left(21 \% \mathrm{O}_{2}\right.$ [-- - ], $40 \% \mathrm{O}_{2}[-0-], 100 \% \mathrm{O}_{2}$ $[-\diamond-])$ at 24 hours, I week, and 4 weeks of age. GSH/GSSG ratio was significantly lower in the $100 \% \mathrm{O}_{2}$ resuscitated group $\left(P<0.01\right.$ versus $21 \%$ and $40 \% \mathrm{O}_{2}$ group; analysis of variance) at 24 hours.
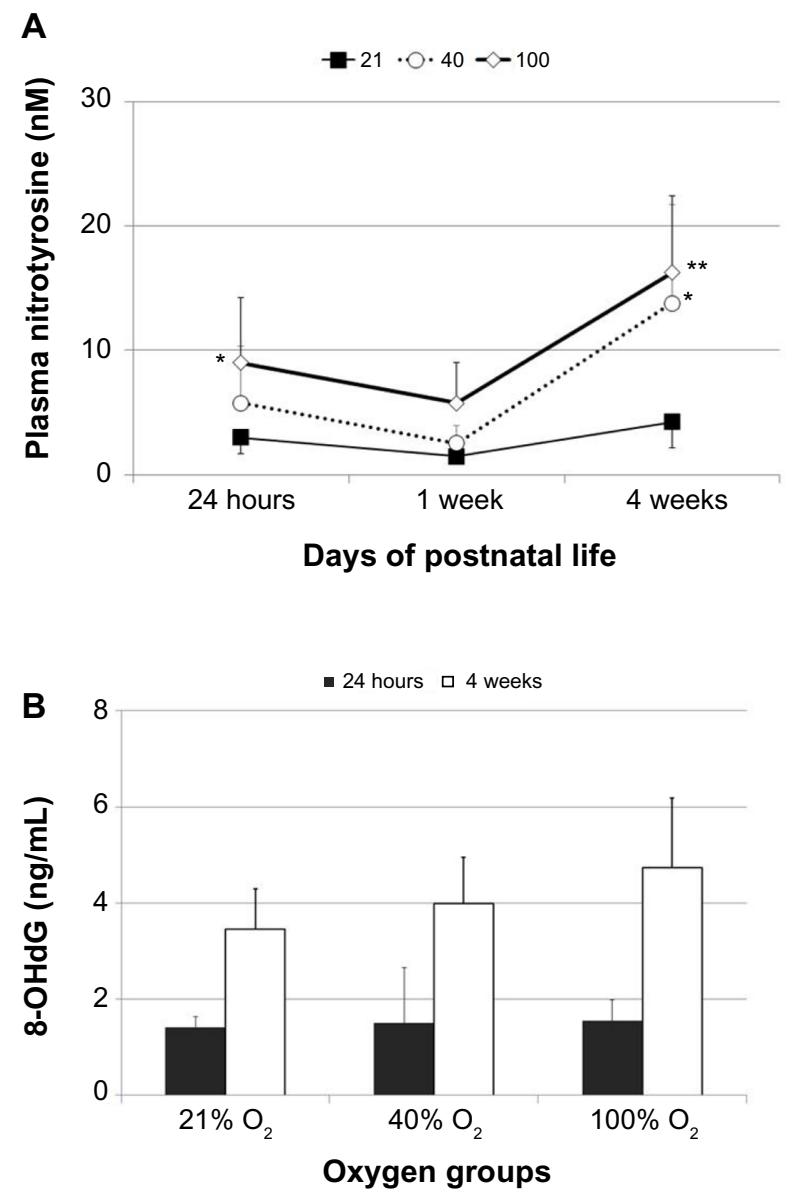

Figure 5 (A) Plasma nitrotyrosine (NT) in the three oxygen resuscitated groups $\left(21 \% \mathrm{O}_{2}[--\mathrm{-}-] ; 40 \% \mathrm{O}_{2}[-0-] ; 100 \% \mathrm{O}_{2}\left[-\mathrm{O}_{-}\right]\right)$at 24 hours, I week, and 4 weeks of age. Babies in the $100 \% \mathrm{O}_{2}$ group had significantly higher NT at 24 hours compared with $21 \% \mathrm{O}_{2}(* P<0.01)$; NT was higher in the $100 \% \mathrm{O}_{2}$ and $40 \% \mathrm{O}_{2}$ resuscitated groups compared with in room-air group over time $(* P<0.01$ versus $21 \% \mathrm{O}_{2} ; * * P<0.003$ versus $21 \% \mathrm{O}_{2}$; analysis of variance). (B) Levels of 8-hydroxydeoxyguanosine (8-OHdG) were similar at 24 hours and at 4 weeks among the groups. However, 8-OHDG levels were significantly higher at 4 weeks than at 24 hours among the groups $(* P<0.000$ I, $t$-test procedure). of oxygen at resuscitation and, in addition, blinding the study gas for the first 10 minutes irrespective of the $\mathrm{SpO}_{2}$, adding value to our results. The major findings include derangement of markers of oxidative stress at 24 hours (GSH/GSSG ratio) and over time (NT), and this could be affected by total oxygen exposure at birth.

The study was designed originally when the 2005 NRP guidelines were in place, at which time the recommendations were to resuscitate premature infants between $21 \%$ and $100 \%$ $\mathrm{O}_{2}$, and for a graded increase or decrease in $\mathrm{O}_{2}$ using blender, with no defined target saturation for the first 10 minutes of age ${ }^{19}$ and no prescribed starting $\mathrm{FiO}_{2}$. Our original enrollment target of 60 patients with 20 infants in each arm was not met during the study period. Low enrollment was mostly due to exclusion of emergent deliveries and lack of appropriate study personnel (who we felt were necessary for this study) in place physically at the time of delivery, which limited our capacity to utilize every birth. Unfortunately, we discontinued the study to stay current with the changes to the neonatal resuscitation guidelines (titrating oxygen for a targeted pre-ductal $\mathrm{SpO}_{2}$ ) in $2010,{ }^{20}$ adding to incomplete and low enrollment. Despite these limitations, the study is useful, as we report for the first time the natural evolution of $\mathrm{SpO}_{2}$ in the first 10 minutes of life during resuscitation with different concentrations of fixed levels of oxygen, including $21 \%$ $\mathrm{O}_{2}$, and how this relates to biomarkers of systemic oxidative stress in infants $<32$ weeks GA.

Requirement for endotracheal intubation was associated with a more premature GA, regardless of the oxygen group, suggesting prematurity as a major factor in PPV/intubation in the $100 \% \mathrm{O}_{2}$ group. All infants in the $100 \% \mathrm{O}_{2}$ group received PPV/intubation in the first 2 minutes of life, which means that intubation was likely due to hypoxia or ventilation issues rather than secondary to apnea from relative and prolonged hyperoxia. The contrast in total oxygen exposure is striking; however, that is mostly by design. Beginning resuscitation with high oxygen such as $100 \% \mathrm{O}_{2}$ resulted in a mean (SD) oxygen load of $38 \%( \pm 20)$, despite aggressive weaning by 30 minutes.

Despite limited subject enrollment, the study increases our understanding of the natural evolution of $\mathrm{SpO}_{2}$ when exposed to three different static oxygen concentrations in the first 10 minutes of life. $\mathrm{SpO}_{2}$ values in the $100 \% \mathrm{O}_{2}$ group were higher compared with the NRP upper limit, suggesting that $100 \% \mathrm{O}_{2}$ is probably not the right concentration for resuscitating premature infants to meet 2010 guidelines on targeted preductal $\mathrm{SpO}_{2}$ at birth. There were no significant differences in $\mathrm{SpO}_{2}$ between the $21 \% \mathrm{O}_{2}$ and $40 \% \mathrm{O}_{2}$ groups. 
Resuscitation with either $21 \% \mathrm{O}_{2}$ or $40 \% \mathrm{O}_{2}$ resulted in $\mathrm{SpO}_{2}$ within the NRP targeted range, especially from 6 to 10 minutes of life. This suggests that premature infants can probably be weaned to $21 \% \mathrm{O}_{2}$ by 6 minutes of life. It is hard to justify $21 \% \mathrm{O}_{2}$ in the first 5 minutes of birth with the small number of infants in our study. GA may be an important factor influencing $\mathrm{O}_{2}$ resuscitation at birth, as extremely premature infants ( $<26$ weeks $\mathrm{GA}$ ) will probably need some oxygen initially and infants $>28$ weeks GA may escape oxygen to maintain $\mathrm{SpO}_{2}$ within the defined targeted range. Multiple studies have addressed the issue by initial oxygen exposure followed by frequent titration to maintain a specific $\mathrm{SpO}_{2}$ range at resuscitation. Titrating from an initial concentration of $100 \% \mathrm{O}_{2}$ was more effective than giving a static concentration of $100 \% \mathrm{O}_{2}$ in maintaining preterm infants in a target $\mathrm{SpO}_{2}(85-92)$ in the first 10 minutes after birth. However, resuscitation with $21 \% \mathrm{O}_{2}$ resulted in a high treatment-failure rate. ${ }^{17} \mathrm{~A}$ previous study has reported that infants resuscitated with $21 \% \mathrm{O}_{2}$ failed to achieve a set target saturation and all infants in the room-air group needed oxygen by 3 minutes of age. ${ }^{18}$ However, resuscitation can be safely initiated in infants $<28$ weeks GA with a lower $\mathrm{FiO}_{2}$ $\left(30 \% \mathrm{O}_{2}\right)$, which then can be adjusted to the infant's needs, reducing the oxygen load to the neonate. ${ }^{16}$ Also, infants randomized to $30 \% \mathrm{O}_{2}$ (compared with to $90 \% \mathrm{O}_{2}$ ) at birth and then titrated to maintain a specific saturation, had lower oxidative stress and reduced incidence of BPD. ${ }^{7}$

In our study, resuscitation with $100 \% \mathrm{O}_{2}$ was associated with a significantly higher GSSG and a lower GSH/GSSG ratio, indicative of oxidative stress at 24 hours of age; however, this effect was not sustained at 4 weeks of age. The absence of any difference in GSH/GSSG at 4 weeks among the groups may in part be due to lack of asphyxial insult or prematurity in these infants, as this has previously been demonstrated in term asphyxiated infants. ${ }^{8}$ However, in preterm infants with mild to moderate asphyxia, total hydroperoxide was significantly higher and redox potential to total hydroperoxide ratio was lower in the $100 \% \mathrm{O}_{2}$ group compared with in the reduced $\mathrm{O}_{2}$ resuscitated group, indicating that oxidative stress can be reduced by lowering the inspired oxygen concentration. ${ }^{2}$ Resuscitation of premature infants with $30 \%$ $\mathrm{O}_{2}$ also decreased oxidative stress, as measured by GSSG/ GSH ratio on days 1 and 3 of life, compared with $90 \% \mathrm{O}_{2}$ resuscitation. ${ }^{7}$ Urinary markers of oxidative stress were also higher in the high-oxygen group, suggesting the detrimental effects of oxygen load at resuscitation. ${ }^{7}$

In the present study, plasma NT was significantly higher in the $100 \% \mathrm{O}_{2}$ and $40 \% \mathrm{O}_{2}$ resuscitated groups over time. The presence of nitrated proteins in the plasma may indicate either inflammation or the formation of peroxynitrite from nitric oxide and superoxide. ${ }^{21}$ In a case-control study, infants who developed BPD had a significantly higher plasma NT on the first day of life than infants who did not develop BPD. ${ }^{15}$ Although our study is limited by small numbers, more infants in the $100 \% \mathrm{O}_{2}$ group developed BPD compared with in the other two groups. Plasma 8-OHdG increased over time; however, levels were not different among the oxygen groups. This may be related to similar birth weight and GA among the groups, as plasma 8-OHdG at birth has been shown to be negatively correlated with birth weight and GA. ${ }^{22}$ There is a paucity of literature on plasma $8-\mathrm{OHdG}$ measurements as they relate to oxygen and oxidative DNA damage in the newborn. However, urinary elimination of oxidized guanosine, as measured by 8 oxodG/2dG ratio, was higher in the first week in the high-oxygen group, implying oxygen at birth induces DNA damage. ${ }^{7}$ Further, 8-OHdG levels determined by ELISA are not highly specific, unlike when determined by mass spectrometry, which may explain the lack of association with the oxygen groups in our study.

We found no significant differences in $\mathrm{SpO}_{2}$ among the three oxygen groups in the first 10 minutes after birth; however, we found difference in oxidative-stress markers among the groups at 24 hours and 4 weeks of age. The $\mathrm{SpO}_{2}$ in the $100 \% \mathrm{O}_{2}$ group was well above the NRP upper limit, whereas that in the $40 \% \mathrm{O}_{2}$ and the $21 \% \mathrm{O}_{2}$ groups bordered the NRP lower limit. Smaller changes in $\mathrm{SpO}_{2}$ are associated with larger changes in arterial $\mathrm{PaO}_{2}$, an optimal measure of assessing oxygenation. Measurement of $\mathrm{SpO}_{2}$, although noninvasive, has reduced sensitivity to hyperoxemia, more so in the first 10 minutes after birth when the relationship between $\mathrm{FiO}_{2}$ and $\mathrm{SpO}_{2}$ is not well established. Also, the $100 \% \mathrm{O}_{2}$ group had higher $\mathrm{O}_{2}$ exposure by 30 minutes of age compared with the other two groups. This could explain a significantly higher GSSG, lower GSH/GSSG ratio, and higher NT in the plasma at 24 hours of age. However, subsequent $\mathrm{O}_{2}$ exposure and lung immaturity may have triggered an inflammatory response leading to the development of BPD. This is probably the reason for subsequent elevation of plasma NT in the $40 \%$ and $100 \% \mathrm{O}_{2}$ groups at 4 weeks. The oxidative and nitrosative stress may also be related to a host of factors - including, among others, hypoxic episodes $;{ }^{23} \mathrm{sex} ;{ }^{24}$ antenatal steroids; $;{ }^{24}$ days on mechanical ventilation; and severity of lung disease, especially in chronically ventilated infants.

\section{Conclusion}

Although multiple studies have addressed issues involving oxygen at resuscitation, the novelty of our study was in keeping the oxygen concentration constant at resuscitation. 
This has helped us to define the natural evolution of $\mathrm{SpO}_{2}$ in the first 10 minutes to three different oxygen concentrations. We have shown that oxygen at resuscitation and total oxygen exposure correlates significantly with markers of oxidant and nitrosative stress. Despite the low number of infants enrolled, the study adds to the literature regarding the role of oxygen at resuscitation and its relation to systemic oxidant stress in premature infants $<32$ weeks GA.

\section{Acknowledgments}

We thank the Wildermuth Foundation, Buffalo, New York, for funding the study (VHK). We acknowledge the loan of pulse oximeters and related supplies by Masimo Corporation, Irvine, California, for use in the study. We wish to thank the respiratory therapists and nurses whose generous efforts made this study possible. We also thank Dr Chang-Xing Ma, $\mathrm{PhD}$, Department of Biostatistics (University at Buffalo, Buffalo, NY), for statistical help.

\section{Disclosure}

The authors declare no conflicts of interest in this work.

\section{References}

1. Frank L, Sosenko IR. Prenatal development of lung antioxidant enzymes in four species. J Pediatr. 1987;110(1):106-110.

2. Ezaki S, Suzuki K, Kurishima C, et al. Resuscitation of preterm infants with reduced oxygen results in less oxidative stress than resuscitation with 100\% oxygen. J Clin Biochem Nutr. 2009;44(1):111-118.

3. Saugstad OD. Oxygen toxicity in the neonatal period. Acta Paediatr Scand. 1990;79(10):881-892.

4. Kumar VH, Patel A, Swartz DD, et al. Exposure to supplemental oxygen and its effects on oxidative stress and antioxidant enzyme activity in term newborn lambs. Pediatr Res. 2010;67(1):66-71.

5. Vento M, Sastre J, Asensi MA, Vina J. Room-air resuscitation causes less damage to heart and kidney than $100 \%$ oxygen. Am J Respir Crit Care Med. 2005;172(11):1393-1398.

6. Solås $\mathrm{AB}$, Kalous $\mathrm{P}$, Saugstad $\mathrm{OD}$. Reoxygenation with 100 or $21 \%$ oxygen after cerebral hypoxemia-ischemia-hypercapnia in newborn piglets. Biol Neonate. 2004;85(2):105-111.

7. Vento M, Moro M, Escrig R, et al. Preterm resuscitation with low oxygen causes less oxidative stress, inflammation, and chronic lung disease. Pediatrics. 2009;124(3):e439-e449.

8. Vento M, Asensi M, Sastre J, García-Sala F, Pallardó FV, Viña J. Resuscitation with room air instead of $100 \%$ oxygen prevents oxidative stress in moderately asphyxiated term neonates. Pediatrics. 2001;107(4):642-647.
9. Saugstad OD. Room air resuscitation-two decades of neonatal research. Early Hum Dev. 2005;81(1):111-116.

10. Tan A, Schulze A, O'Donnell CP, Davis PG. Air versus oxygen for resuscitation of infants at birth. Cochrane Database Syst Rev. 2005;(2):CD002273.

11. Patel A, Lakshminrusimha S, Ryan RM, et al. Exposure to supplemental oxygen downregulates antioxidant enzymes and increases pulmonary arterial contractility in premature lambs. Neonatology. 2009;96(3): $182-192$.

12. Saugstad OD. Bronchopulmonary dysplasia-oxidative stress and antioxidants. Semin Neonatol. 2003;8(1):39-49.

13. Ogihara T, Okamoto R, Kim HS, et al. New evidence for the involvement of oxygen radicals in triggering neonatal chronic lung disease. Pediatr Res. 1996;39(1):117-119.

14. Schock BC, Sweet DG, Halliday HL, Young IS, Ennis M. Oxidative stress in lavage fluid of preterm infants at risk of chronic lung disease. Am J Physiol Lung Cell Mol Physiol. 2001;281(6): L1386-L1391.

15. Banks BA, Ischiropoulos H, McClelland M, Ballard PL, Ballard RA. Plasma 3-nitrotyrosine is elevated in premature infants who develop bronchopulmonary dysplasia. Pediatrics. 1998;101(5):870-874.

16. Escrig R, Arruza L, Izquierdo I, et al. Achievement of targeted saturation values in extremely low gestational age neonates resuscitated with low or high oxygen concentrations: a prospective, randomized trial. Pediatrics. 2008;121(5):875-881.

17. RabiY, Singhal N, Nettel-Aguirre A. Room-air versus oxygen administration for resuscitation of preterm infants: the ROAR study. Pediatrics. 2011;128(2):e374-e381.

18. Wang CL, Anderson C, Leone TA, Rich W, Govindaswami B, Finer NN. Resuscitation of preterm neonates by using room air or $100 \%$ oxygen. Pediatrics. 2008;121(6):1083-1089.

19. American Heart Association, American Academy of Pediatrics. 2005 American Heart Association (AHA) guidelines for cardiopulmonary resuscitation (CPR) and emergency cardiovascular care (ECC) of pediatric and neonatal patients: neonatal resuscitation guidelines. Pediatrics. 2006;117(5):e1029-e1038.

20. Kattwinkel J, Perlman JM, Aziz K, et al. Part 15: neonatal resuscitation: 2010 American Heart Association Guidelines for Cardiopulmonary Resuscitation and Emergency Cardiovascular Care. Circulation. 2010;122(18 Suppl 3):S909-S919.

21. Ischiropoulos H. Biological tyrosine nitration: a pathophysiological function of nitric oxide and reactive oxygen species. Arch Biochem Biophys. 1998;356(1):1-11.

22. Negi R, Pande D, Kumar A, Khanna RS, Khanna HD. In vivo oxidative DNA damage and lipid peroxidation as a biomarker of oxidative stress in preterm low-birthweight infants. J Trop Pediatr. 2012;58(4): 326-328.

23. Escobar J, Teramo K, Stefanovic V, et al. Amniotic fluid oxidative and nitrosative stress biomarkers correlate with fetal chronic hypoxia in diabetic pregnancies. Neonatology. 2013;103(3):193-198.

24. Vento M, Aguar M, Escobar J, et al. Antenatal steroids and antioxidant enzyme activity in preterm infants: influence of gender and timing. Antioxid Redox Signal. 2009;11(12):2945-2955.

Research and Reports in Neonatology

\section{Publish your work in this journal}

Research and Reports in Neonatology is an international, peer-reviewed, open access journal publishing original research, reports, editorials, reviews and commentaries on neonatal health. The manuscript management system is completely online and includes a very quick and fair

peer-review system. Visit http://www.dovepress.com/testimonials.php to read real quotes from published authors. 